\title{
Vitamin B3 mystery challenge
}

\author{
Lucia D'Ulivo ${ }^{1}$
}

Published online: 29 June 2018

(C) Springer-Verlag GmbH Germany, part of Springer Nature 2018

We would like to invite you to participate in the Analytical Challenge, a series of puzzles to entertain and challenge our readers. This special feature of "Analytical and Bioanalytical Chemistry" has established itself as a truly unique quiz series, with a new scientific puzzle published every three months. Readers can access the complete collection of published problems with their solutions on the ABC homepage at http://www.springer.com/abc. Test your knowledge and tease your wits in diverse areas of analytical and bioanalytical chemistry by viewing this collection.

In the present challenge, vitamin B3 is the topic. And please note that there is a prize to be won (a Springer book of your choice up to a value of $€ 100)$. Please read on...

\section{Meet the challenge}

Niacin or nicotinic acid (Fig. 1), also known as part of vitamin B3 complex, is an essential nutrient, and the US Food and Drug Administration recommends a daily intake of $16 \mathrm{mg}$ niacin equivalents. As a precursor of NAD and NADP coenzymes, it plays an important role in human metabolism, DNA repair, and normal functioning of the nervous system [1]. A severe deficiency of niacin causes pellagra, a disease characterized by symptoms such as diarrhea, dermatitis, and dementia [1].

Christopher Columbus brought the corn plant to Europe and it quickly became a staple food largely due its high yields per hectare compared to wheat. Unfortunately, the widespread use of corn was followed by a disease that we now call pellagra. The connection between corn and this disease was first established by a Catalan physician Gaspar Casal. Pellagra was already an epidemic in Europe in the 18 th century, and in the first half of the 20th century it

Lucia D'Ulivo

lucia.dulivo@gmail.com

1 Ottawa, Canada

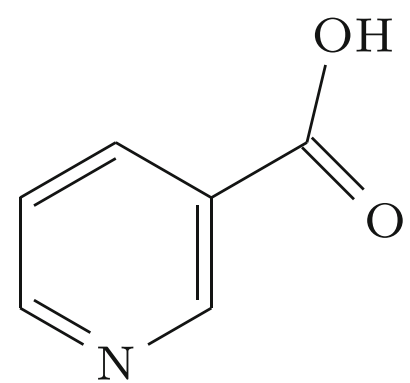

Fig. 1 Chemical structure of niacin

also started its spread in the United States of America, particularly among the poorest social classes. The actual cause of pellagra was not clear, and Joseph Goldberger, a Hungarian-American medical doctor, made a career out of solving its origins. Goldberger noticed that persons who followed a varied diet, rich in meat, diary products, and fresh foodstuffs, were much less prone to develop pellagra. Goldberger made significant efforts to isolate the so-called pellagra-preventing factor for which he was nominated for the Nobel Prize in Physiology and Medicine. He died in 1929 and it was the American biochemist Conrad Elvehjem who discovered soon after that niacin was capable of preventing pellagra [2]. This discovery was of crucial importance in building up a pellagra-prevention campaign, along with a food-fortification programs. Thanks to the work of Goldberger and Elvehjem, pellagra was eradicated in the USA and Europe, although pellagra outbreaks still occur in emergency-affected populations in Africa.

This story might suggest that maize does not contain any niacin. However, that is not the case, as niacin is present at significant concentrations in corn [3]. Interestingly, Mesoamerican populations, among which poverty was diffused and food variety limited, had used corn as a staple food for centuries, yet they never developed pellagra.

Why did maize flour provoke pellagra in Europe and the USA while populations in Central and South America never developed this disease? 


\section{References}

1. Eitenmiller LY, Ronald R, Landen JWO. Vitamin analysis for the health and food science. Boca Raton: CRC Press; 2008.

2. Rajakumar K. Pellagra in the United States: a historical perspective. South Med J. 2000;93:272-7.

3. Carpenter. The relationship of pellagra to corn and the low availability of niacin in cereals. Experientia Suppl. 1983;44:197222.
We invite our readers to participate in the Analytical Challenge by solving the puzzle above. Please send the correct solution to abc-challenge@springer.com by September 1, 2018. Make sure you enter "Vitamin B3 mystery challenge" in the subject line of your e-mail. The winner will be notified by e-mail and his/her name will be published on the "Analytical and Bioanalytical Chemistry" homepage at http://www.springer.com/abc and in the journal (volume 411/issue 1) where readers will find the solution and a short explanation.

The next Analytical Challenge will be published in 410/25, October 2018. If you have enjoyed solving this Analytical Challenge you are invited to try the previous puzzles on the ABC homepage. 